This item is the archived peer-reviewed author-version of:

\title{
Phylogenetic analysis of the Trypanosoma genus based on the heat-shock protein
} 70 gene

\section{Reference:}

Fraga Jorge, Fernandez-Calienes Ayme, Margarita Montalvo Ana, Maes Ilse, Deborggraeve Stijn, Buscher Philippe, Dujardin Jean-Claude, Van der Auwera Gert.- Phylogenetic analysis of the Trypanosoma genus based on the heat-shock protein 70 gene

Infection, genetics and evolution - ISSN 1567-1348 - 43(2016), p. 165-172

Full text (Publisher's DOI): http://dx.doi.org/doi:10.1016/J.MEEGID.2016.05.016

To cite this reference: http://hdl.handle.net/10067/1349330151162165141 


\section{Accepted Manuscript}

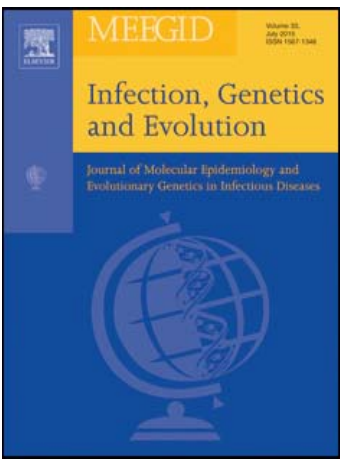

Phylogenetic analysis of the Trypanosoma genus based on the heat-shock protein 70 gene

Jorge Fraga, Aymé Fernández-Calienes, Ana Margarita Montalvo, Ilse Maes, Stijn Deborggraeve, Philippe Büscher, Jean-Claude Dujardin, Gert Van der Auwera

PII:

DOI:

S1567-1348(16)30188-5

Reference: doi: 10.1016/j.meegid.2016.05.016

MEEGID 2749

To appear in:

Received date: 22 December 2015

Revised date: $\quad 10$ May 2016

Accepted date: 11 May 2016

Please cite this article as: Fraga, Jorge, Fernández-Calienes, Aymé, Montalvo, Ana Margarita, Maes, Ilse, Deborggraeve, Stijn, Büscher, Philippe, Dujardin, Jean-Claude, Van der Auwera, Gert, Phylogenetic analysis of the Trypanosoma genus based on the heatshock protein 70 gene, (2016), doi: 10.1016/j.meegid.2016.05.016

This is a PDF file of an unedited manuscript that has been accepted for publication. As a service to our customers we are providing this early version of the manuscript. The manuscript will undergo copyediting, typesetting, and review of the resulting proof before it is published in its final form. Please note that during the production process errors may be discovered which could affect the content, and all legal disclaimers that apply to the journal pertain. 
Phylogenetic analysis of the Trypanosoma genus based on the heat-shock protein 70 gene

Jorge Fraga ${ }^{1}$, Aymé Fernández-Calienes ${ }^{1}$, Ana Margarita Montalvo ${ }^{1}$, Ilse Maes ${ }^{2}$, Stijn Deborggraeve $^{2}$, Philippe Büscher ${ }^{2}$, Jean-Claude Dujardin ${ }^{2,3}$, Gert Van der Auwera ${ }^{2}$

1- Parasitology Department, Institute of Tropical Medicine Pedro Kouri, La Havana, Cuba.

2- Department of Biomedical Sciences, Institute of Tropical Medicine, Antwerp, Belgium.

3- Department of Biomedical Sciences, Antwerp University, Antwerp, Belgium.

Corresponding author: Gert Van der Auwera. Department of Biomedical Sciences, Institute of Tropical Medicine (ITM), Nationalestraat 155, 2000 Antwerp, Belgium.

e-mail: gvdauwera@itg.be

Tel: +32 32476586 / Fax: +32 32476359

\section{Footnote:}

Note: Nucleotide sequence data reported in this paper are available in GenBank, EMBL and DDBJ databases under the accession numbers KC959988- KC960011; KP208734-KP208748; KP257564-KP257565. 


\begin{abstract}
Trypanosome evolution was so far essentially studied on the basis of phylogenetic analyses of small subunit ribosomal RNA (SSU-rRNA) and glycosomal glyceraldehyde-3phosphate dehydrogenase (gGAPDH) genes. We used for the first time the $70 \mathrm{kDa}$ heat-shock protein gene ( $h s p 70)$ to investigate the phylogenetic relationships among 11 Trypanosoma species on the basis of 1380 nucleotides from 76 sequences corresponding to 65 strains. We also constructed a phylogeny based on combined datasets of SSU-rDNA, gGADPH and $h s p 70$ sequences. The obtained clusters can be correlated with the sections and subgenus classifications of mammal-infecting trypanosomes except for T. theileri and T. rangeli. Our analysis supports the classification of Trypanosoma species into clades rather than in sections and subgenera, some of which being polyphyletic. Nine clades were recognized: T. carassi, T. congolense, T. cruzi, T. grayi, T. lewisi, T. rangeli, T. theileri, T. vivax and Trypanozoon. These results are consistent with existing knowledge of the genus' phylogeny. Within the T. cruzi clade, three groups of T. cruzi discrete typing units could be clearly distinguished, corresponding to TcI, TcIII, and TcII+V+VI, while support for TcIV was lacking. Phylogenetic analyses based on hsp70 demonstrated that this molecular marker can be applied for discriminating most of the Trypanosoma species and clades.
\end{abstract}

Key words: Trypanosoma; Trypanozoon; phylogeny; HSP70; heat-shock protein. 


\section{Introduction}

Parasites from the genus Trypanosoma (Kinetoplastida: Trypanosomatidae) are ubiquitous protozoans that infect a wide range of animals, including leeches, insects, fish, amphibians, reptiles, birds, and mammals, and are the causative agents of some of the most neglected human and animal diseases. The genus Trypanosoma is considered a monophyletic group, sharing a common ancestor that dates back about 100 million years ago (Barrett et al., 2003; Stevens and Gibson, 1999).

The classification established by Hoare was based on morphology and development in the vector (Hoare, 1972) (Table 1). Mammal-infecting Trypanosoma species were separated into sections: Salivaria and Stercoraria. The salivarian trypanosomes were further subdivided into four subgenera: Trypanozoon, Duttonella, Nannomonas and Pycnomonas. The Stercoraria comprised three subgenera: Schizotrypanum, Megatrypanum, and Herpetosoma (Vickerman, 1976). Since some of these groups are polyphyletic and lack evolutionary and taxonomic relevance, more recently some authors suggested classifying the genus into clades, based on the small subunit rRNA (SSU-rRNA) and glycosomal glyceraldehyde 3-phosphate dehydrogenase (gGAPDH) genes (Simpson et al., 2006; Stevens, 2008; Stevens and Gibson, 1999; Stevens and Rambaut, 2001) (Table 1): the 'T. brucei clade' with T. brucei and relatives, which typically are transmitted by tsetse flies (with exceptions); the 'T. cruzi clade' with the predominantly New World species of $T$. cruzi and relatives (typically transmitted by triatomine bugs); a 'rodent clade' (presumably transmitted primarily by fleas); an 'avian clade' (transmitted primarily by black flies and hippoboscid flies); and an `aquatic clade’ (transmitted by leeches and insects).

In spite of the information provided by DNA sequence analysis, trypanosomatid phylogeny and evolutionary relationships have not been firmly established (Hughes and Piontkivska, 2003; Kelly et al., 2014; Votýpka et al, 2015). Phylogenies among the Trypanosoma 
have varied depending on the gene sequences analyzed, the number of taxa included, the choice of outgroup, and the phylogenetic methodology employed (Leonard et al., 2011). Especially the monophyly and clade classification of Trypanosoma have been subject of debate. Two molecular markers, the SSU-rRNA and gGAPDH genes, have been extensively used for phylogenetic studies within the entire Trypanosoma genus, and for establishing relationships with other genera of the Trypanosomatidae family (Hamilton et al., 2004, 2007; Hughes and Piontkivska, 2003; Stevens and Gibson, 1999).

Another promising evolutionary marker, the $70 \mathrm{kDa}$ heat-shock protein (HSP70), has so far not been applied to Trypanosoma, even though it was proven useful to study various parasites such as Cryptosporidium spp. (Langkjaer et al., 2007; Sulaiman et al., 2000;), Babesia spp. (Yamasaki et al., 2002, 2007), Giardia spp. (Arisue et al., 2002b), Entamoeba spp. (Arisue et al., 2002b), Microsporidium spp. (Arisue et al., 2002b), Blastocystis hominis (Arisue et al., 2002a), and the kinetoplastid Leishmania genus (Fraga et al., 2010, 2013). HSP70 proteins are highly conserved across prokaryotes and eukaryotes both in sequence and function, and have great importance as molecular chaperones and in protein folding and transport (Hartl and Hayer-Hartl, 2002). They are a subfamily of the larger HSP70 family (Folgueira and Requena, 2007), which could play a major role in environmental adaptations of trypanosomes (Drini et al., unpublished results). The $h s p 70$ subfamily genes used here are arranged as a tandem repeat array in a head to tail manner, of which in T. cruzi at least seven copies are present (Requena et al., 1988). Genes encoding cytoplasmic HSP70s were among the first kinetoplastid genes to be cloned and characterized because of their conserved nature (Folgueira and Requena, 2007). In this study we investigate the phylogenetic relationships among several species of the Trypanosoma genus using partial coding sequences of the hsp70 gene, and compare the results with those obtained with other markers. 


\section{Material and Methods.}

\subsection{Strains and isolates}

Figure 1 presents the geographical origin and the species of the strains and isolates used in our study (full details in Table S1). Our main goal was to cover the species of particular relevance to human and animal health, while only including other strains that were available in our lab at the time of analysis, or from which the sequence could be retrieved from public repositories (see further). The analysis included 11 species of Trypanosoma. Among these were the mammal infecting Trypanosoma species from the subgenus and sections described by Hoare (1972), and trypanosomes isolated from fish and reptiles. Parasite isolates and DNA were obtained from different laboratories and collections acknowledged at the end of this article. The reference species identification and genotype was based on various data such as multilocus sequence typing (MLST), multilocus enzyme electrophoresis (MLEE), multilocus microsatellite typing (MLMT), restriction fragment size polymorphism analysis, and sequencing.

\subsection{PCR amplification of $h s p 70$}

A PCR product of $1422 \mathrm{bp}$, corresponding to positions 435-1856 of the complete T. cruzi CL Brener gene (2034 bp, GenBank accession XM_812645) was amplified from 41 strains listed in Table S1, using primers HSP70sen and HSP70ant (Table 2) from Garcia et al. (2004). The reaction mix $(50 \mu \mathrm{L})$ contained $1 \mathrm{x}$ standard PCR buffer including $1.5 \mathrm{mM} \mathrm{MgCl}_{2}, 1 \mathrm{x}$ Q-buffer, $200 \mu \mathrm{M}$ of each deoxynucleoside triphosphate, 0.5 U HotStarTaq Plus DNA polymerase (Qiagen, Hilden, Germany), $0.4 \mu \mathrm{M}$ of each primer, and $10 \mathrm{ng}$ of genomic DNA isolated from parasite cultures. The thermal cycling parameters of the assay were: initial denaturation at $95^{\circ} \mathrm{C}$ for $5 \mathrm{~min}$, followed by 35 cycles consisting of $94^{\circ} \mathrm{C}$ for $40 \mathrm{~s}-61^{\circ} \mathrm{C}$ for $1 \mathrm{~min}-72^{\circ} \mathrm{C}$ for $2 \mathrm{~min}$, and a final 
extension step of $8 \mathrm{~min}$ at $72^{\circ} \mathrm{C}$. Amplicons were visualized on a $2 \%$ agarose gel, and sequenced directly without molecular cloning.

\subsection{DNA sequencing}

Sequences were generated with the primers listed in Table 2, using the dideoxy nucleotide chemistry from the ABI PRISM BigDye ${ }^{\mathrm{TM}}$ Terminator cycle sequencing kit (Perkin Elmer, Foster City, CA, USA). They were analyzed on an ABI 3730 automated sequencer (Perkin Elmer). For phylogenetic analysis only the region between the primers was retained, i.e. 1380 out of the 1422 nucleotides. Additional hsp70 sequences (Table S1) where obtained from BLAST searches in the following databases: GeneDB (http://www.genedb.org), TritrypDB (http://www.tritrypdb.org) and GenBank (http://www.ncbi.nlm.nih.gov). Finally, some sequences were taken from unpublished whole genome sequences obtained from the Institute of Tropical Medicine (Antwerp, Belgium); the French Agency for Food, Environmental and Occupational Health \& Safety; the University of Glasgow (UK) and the Food and Agriculture Organization (Italy).

\subsection{Phylogenetic analysis}

The obtained sequences were aligned with previously published sequences as listed in Table S1, using the software package MEGA (Molecular Evolutionary Genetic Analysis Version 5.05, Tamura et al., 2011, www.megasoftware.net). As no length variation is present between the sequences, the alignment was straightforward and no alignment algorithm was needed. The same software was used to build phylogenetic trees with both distance and character-based methods, and to analyze synonymous versus non-synonymous nucleotide substitutions. The number of synonymous differences per synonymous site, and the number of non-synonymous differences 
per non-synonymous site were averaged over all Trypanosoma sequence pairs, using the NeiGojobori method (Nei and Gojobori, 1986). As for several strains more than one sequence was available (see Table S1), only one sequence was retained for this analysis.

Neighbor-Joining phylogenies were constructed using the Kimura 2-parameter model (Kimura, 1980) for pairwise distance calculations. Character-based phylogenetic analyses were performed as well, with Maximum Parsimony (Eck and Dayhoff, 1966; Fitch, 1971) and Maximum Likelihood (ML) (Felsenstein, 1985) methods. The ML analysis was done under the General Time Reversible and Gamma Distributed model, as selected using the Akaike information criterion in MEGA 5.05. Distances from predicted amino acid sequences were determined with the p-distance model. Leishmania spp. and Paratrypanosoma confusum were included as outgroups (Table S1). The support of groups was assessed by the bootstrap method (Felsenstein, 1985) with 2000 replicates.

Additionally, a phylogenetic network was inferred from Kimura 2-parameter distances with the Neighbor-Net method in SplitsTree4 (Huson, 1998; Huson and Bryant, 2006). Such networks can depict alternative evolutionary paths supported by the data set, as they do not enforce a single bifurcating dendrogram. Bootstrap was performed with 2000 replicates.

Finally the SSU-rDNA, gGADPH, and $h s p 70$ sequences (Table S2) were concatenated and analyzed with Neighbor-Joining, Maximum Parsimony, and Maximum Likelihood, as described above.

\section{Results.}

\subsection{Sequence characteristics}

A fragment of $1380 \mathrm{bp}$ of the $h s p 70$ genes from 41 strains of nine Trypanosoma species was sequenced (Fig.1, Table S1). These were aligned with 35 previously available sequences of 8 
Trypanosoma species, amounting to a total of 76 sequences of 65 strains from 11 Trypanosoma species. For nine strains more than one $h s p 70$ sequence was available, originating from different sources. For five strains (CL Brener, Tre, H14, Esm and STIB805) one to six nucleotides differed between sequences of the same strain, while the sequences from each of the remaining four strains (927/4GUTat10.1, ILRAD3000, ABBA and Y486) were identical. There were no sequence ambiguities in 55 out of the 76 sequences, and in total 39 positions in the remaining 21 sequences showed the presence of 2-base ambiguities.

The gene fragments of Trypanosoma spp. were GC rich (55.8-65.6\%), with a similarity between species ranging from 75 to $100 \%$ (overall average $86.8 \%$ ). The nucleotide sequence variation allowed discriminating all parasite species included in this study, except those of the "Trypanozoon" clade that grouped T. brucei gambiense, T. b. rhodesiense, T. b. brucei, T. evansi, and T. equiperdum. In total 526 nucleotide positions (38.1\%) were polymorphic and 412 positions $(29.8 \%)$ were parsimony informative. The deduced amino acid sequences (459 amino acids) revealed substitutions at 132 positions (28.8\%), of which 83 sites (18.1\%) were parsimony informative. The number of non-synonymous substitutions per non-synonymous site $d N$ was $3.2 \%$, while the number of synonymous substitutions per synonymous site $d S$ was $40.2 \%$, hence $d N / d S<1$.

\subsection{Phylogenetic analysis}

The Neighbor-Joining tree constructed from hsp 70 sequences is presented in Figure 2, where the sections and subgenera defined by Hoare (1972) and the comparison with two other genes are included. From the selection of species included in this analysis, only two subgenera do not follow the Hoare (1972) classification. First, Herpetosoma forms a paraphyletic group, with Schizotrypanum branching between T. rangeli and T. lewisi. Second, Megatrypanum is not 
supported as a Stercoraria section. Based on hsp70, nine groups are recognized: T. carassi, Trypanozoon, T. congolense, T. vivax, T. theileri, T. grayi, T. lewisi, T. rangeli and T. cruzi. The Trypanozoon clade includes T. brucei gambiense, T. b. rhodesiense, T. b. brucei, T. evansi, and T. equiperdum. The T. cruzi clade includes T. cruzi and T. cruzi marinkellei.

All these clusters were also observed in Maximum Parsimony (Fig. S1) and Maximum Likelihood phylogenies (Fig. S2). The bootstrap values from these trees are also indicated in Fig. 2, and exceed $95 \%$ with all methods. This indicates that the derived groups are robust and not dependent of the choice of evolutionary models underlying the various tree-building algorithms. Trees based upon amino acid sequences (Fig. S3) did not conflict the nucleotide-based phylogenies.

Figure 3 displays a phylogenetic network of the Trypanosoma sequences, thereby excluding Leishmania and Paratrypanosoma confusum. The groups that could be reliably identified using conventional phylogenetic analysis are also recovered from the network (Fig. 3A). Figure 3A shows a separation of T. cruzi and T. cruzi marinkellei as subgroups within the T. cruzi clade. In the $T$. rangeli cluster two groups can be distinguished (Fig. 3B). Species or subspecies in the Trypanozoon cluster cannot be distinguished (Fig. 3C). Three genetic groups are seen in T. cruzi (Fig. 2; Fig. 3D), corresponding to Discrete Typing Units (DTUs, see Zingales et al., 2012) TcI and TcIII, and DTUs TcII, TcV, and TcVI which do not form separate entities, while support for TcIV was lacking.

In order to appraise whether a combined analysis of SSU-rDNA, gGADPH and $h s p 70$ sequences would further clarify the phylogenic relationships within the Trypanosoma genus, SSU-rDNA, gGADPH and $h s p 70$ sequences from 9 species were concatenated (Fig. 4). The analysis was consistent with single gene analysis, with few exeptions. First, T. theileri clustered consistently with the Stercoraria with bootstrap support of nearly $100 \%$ in all trees. Second, 
T. vivax clearly grouped with the Trypanozoon-T. congolense cluster with $100 \%$ bootstrap support in all trees.

\section{Discussion}

This is the first time that $h s p 70$ sequences have been exploited for studying the phylogeny of the Trypanosoma genus. The $d N / d S$ ratio of 0.08 indicates that positive selection did not play a major role in the evolution of the gene, but that instead purifying selection took place to preserve the HSP70 functionality. This includes transport of proteins between cellular compartments, removal of misfolded proteins, folding and refolding of proteins, prevention and dissolution of protein aggregation, and control of regulatory proteins (Requena et al., 2015). Further studies are needed to assess the impact of the observed $h s p 70$ diversity on the host-parasite relationship (Folgueira and Requena, 2007).

Within strains, two types of variations between $h s p 70$ sequences were observed. On the one hand, sequences from different sources derived from the same strain were occasionally dissimilar. On the other hand, some sequences contained ambiguous nucleotides. Although such ambiguous sites can result from an unclear sequence chromatogram, they can also represent genuine sequence variation. Two phenomena can account for these observed intra-strain sequence differences. One possibility is that the strains contain a mix of parasites, having one or the other observed nucleotide. The other possibility is that all parasites from a particular strain are identical, but that differences exist between the tandemly repeated copies of the $h s p 70$ array (Folgueira and Requena, 2007). In order to decide between both options, clones derived from single parasites must be analyzed, and the sequencing strategy must allow revealing intra-parasite variation. 
Our hsp70 analysis supports the classification in the clades proposed by Simpson et al. (2006), which was previously derived from SSU-rRNA and gGAPDH phylogenies (Simpson et al., 2006; Stevens, 2008; Stevens and Gibson, 1999; Stevens and Rambaut, 2001). We cannot draw conclusions regarding the monophyly of the aquatic (T. carassi $\mathrm{TrCa})$, crocodile (T. grayi ANR4) and rodent (T. lewisi ULBPU) clades because they were represented by a single strain. The separation of aquatic and terrestrial Trypanosoma was clearly shown, and confirms data from SSU-rRNA and gGADPH genes (Cavazzana et al., 2010; Hamilton et al., 2004; 2009; Lima et al., 2013; Stevens, 2008; Stevens and Gibson, 1999; Stevens and Rambaut, 2001). The deep split between aquatic and terrestrial clades provides evidence in support of parasite co-evolution with vertebrate hosts and vectors. The Hoare (1972) classification on the contrary was not supported due to the paraphyletic status of Herpetosoma and the lack of support of Megatrypanum as part of the Stercoraria.

Different authors proposed to include in the T. brucei clade the species T. congolense, T. vivax and other tsetse fly transmitted species (T. simiae and T. godfreyi), based on the analysis of SSU-rRNA and gGADPH (Cavazzana et al., 2010; Hamilton et al., 2004; Lima et al., 2013; Simpson et al., 2006; Stevens, 2008; Stevens and Gibson, 1999; Stevens and Rambaut, 2001). Also in our analysis T. brucei, T. congolense, and T. vivax grouped together in support of this clade. Nevertheless, in all analyses T. congolense and T. vivax formed distinct entities, and thus remained recognizable as separate species (Fig. 2). We should note that for $T$. congolense we only analyzed the Savannah subtype, and not the Forest and Kilifi subtypes. Equally so, our T. vivax sample did not include any strains from South America, only from Africa (Table S1).

The Trypanozoon subgenus forms a monophyletic cluster, but its constituent (sub-)species (T. brucei brucei, T. b. rhodesiense, T. b. gambiense, T. evansi, and T. equiperdum) were not supported as separate groups, neither by $h s p 70$ nor by other markers. The monophyly of 
Trypanozoon was also observed from satellite DNA repeats, ITS1-rDNA, and SSU-rDNA sequences (Amer et al., 2011; Cortez et al., 2006; Gibson, 2007; Stevens and Gibson, 1999). T. evansi and T. equiperdum hence are not monophyletic clades and do not qualify for species status.

Within the T. brucei clade reported by Simpson et al. (2006), our analysis identified T. vivax as the first diverging species, but it has a controversial status. Several reports agree with $h s p 70$ and the combined analysis of SSU-rDNA, gGADPH and $h s p 70$ sequences: SSU-rRNA, LSU-rRNA and gGAPDH genes placed T. vivax in the T. brucei clade (Hamilton et al., 2004; Lukeš et al., 1997, Stevens and Gibson, 1999). In addition, some authors identified T. vivax as a distant member of the Salivaria section as part of the African tsetse fly-transmitted group (Amer et al., 2011; Cortez et al., 2006; Hughes and Piontkivska, 2003). On the contrary, in some analysis it appeared apart from the other African trypanosomes and outside all other Trypanosomatidae and Bodonidae using SSU-rDNA (Hughes and Piontkivska, 2003).

In our analysis based on $h s p 70$ sequence alone, $T$. theileri did not convincingly group with either Stercoraria nor with Salivaria species. Its position in the Trypanosoma genus has been matter of debate, and no clear relationships could hitherto be established. Some studies demonstrated that $T$. theileri was closer to $T$. cruzi than to the T. brucei clade, using SSU-rRNA and gGAPDH genes (Cortez et al., 2006; Hamilton et al., 2004, 2007; Rodriguez et al., 2006). Also the combined analysis of SSU-rDNA, gGADPH and $h s p 70$ sequences grouped $T$. theileri with the Stercoraria. However, other studies showed contradictory results using the same genes (Cavazzana et al., 2010; Lima et al., 2013). Our results support $T$. theileri as an independent clade as proposed by Simpson et al. (2006), Rodriguez et al. (2006) and Hamilton et al. (2007).

Based on $h s p 70$ alone, $T$. grayi appeared as an independent taxon, not clearly linked to any other group included in our analysis. However, in the concatenated analysis based on SSU- 
rDNA+gGADPH+hsp70 sequences, $T$. grayi is clearly more related to the $T$. cruzi clade than to the T. brucei clade, and this is supported by bootstrap values between 97 and 100\%, which clearly demonstrates the added value of concatenating different genes. Also Kelly et al. (2014) concluded that $T$. grayi relates more to $T$. cruzi than to T. brucei, but SSU-rRNA and gGAPDH placed it in a clade separate from both T. cruzi and T. brucei, often with other reptile or bird trypanosomes (Hamilton et al., 2004; 2007; Stevens et al., 1999; Kelly et al., 2014). Finally, in the concatenated analysis $T$. grayi and $T$. theileri are deriving from the same branch, albeit with weak bootstrap support.

The $h s p 70$ phylogeny and the combined analysis based on SSU-rDNA+gGADPH+hsp 70 sequences supports the T. cruzi clade as described by Simpson et al. (2006) (Fig. 2, Table 1). Indeed, the $h s p 70$ gene identified $T$. rangeli as a sister clade of $T$. cruzi and $T$. cruzi marinkellei, as did other molecular markers such as the SSU-rRNA, cathepsin L-like proteases, cytochrome b and gGAPDH genes (Maia da Silva et al., 2004, 2007, 2009; Ortiz et al., 2009; Stevens and Gibson, 1999; Stevens and Rambaut, 2001). Traditionally, T. rangeli is classified in the subgenus Herpetosoma of Stercoraria together with the subgenus' type species T. lewisi, but in our analysis Herpetosoma is paraphyletic. Añez (1982) proposed removing T. rangeli from the subgenus Herpetosoma, creating the subgenus Tejeraia within the Salivaria section. Other authors suggested reclassification in the subgenus Schizotrypanum, or discontinued the use of subgenus names altogether based on phylogenetic analysis with SSU-rRNA, gGAPDH, cathepsin L-like proteases, cytochrome b, and spliced-leader RNA genes (Maia da Silva et al., 2004, 2007, 2009; Ortiz et al., 2009; Stevens and Gibson, 1999; Stevens and Rambaut, 2001).

The $h s p 70$ analysis clearly identified two lineages within T. rangeli (Fig. 2, Fig. 3B). Previously, two main genetic lineages were defined based on kinetoplast DNA (kDNA): KP1(+) and KP1(-) (Vallejo et al., 1999, 2003, 2009). In addition, ITS-rDNA and spliced leader genes 
identified at least five lineages (TrA-E) within T. rangeli (Maia da Silva et al., 2004, 2007). As we do not dispose of these lineage identifications for the strains included in our study, we could not correlate these subdivisions with the two $h s p 70$ clades.

T. cruzi is one of the species of the subgenus Schizotrypanum and a heterogeneous monophyletic clade within the Trypanosoma genus (Hoare, 1972; Zingales et al., 2012). It is currently accepted that there are at least six defined genetic groups or discrete typing units (DTUs) or near-clades (clades that are blurred by infrequent inter-lineage genetic recombination) (Tibayrenc and Ayala, 2012): TcI-TcVI (Miles et al., 2009; Zingales et al., 2012). Three groups were clearly supported in the hsp70 network (Fig. 3D), corresponding to TcI, TcIII, and $\mathrm{TcII}+\mathrm{V}+\mathrm{VI}$ isolates. As $\mathrm{TcV}$ and $\mathrm{TcVI}$ have arisen by hybridization of TcII and TcIII (Brisse et al., 2000; Ferreira and Briones, 2012; Flores-Lopez and Machado, 2011; Westenberger et al., 2005), it is not surprising that their $h s p 70$ sequences are linked to one of both, in particular TcII (Caballero et al., 2015; Lima et al., 2015; Westenberger et al., 2005). Based on hsp70 it was hence not possible to discriminate the DTUs TcII, TcV, and TcVI. The bootstrap value of the split defining TcIV was only 58.2, indicating that our data set does not strongly support this DTU, but nor does it support any other affiliation of the two TcIV strains. Two genotypes related to T. cruzi are restricted to bats: Tc-bat and T. cruzi marinkellei (Lima et al., 2012a; Marcili et al., 2009). Genealogy of $h s p 70$ genes inferred in this study confirmed T. cruzi marinkellei isolates a sister clade of human T. cruzi isolates, both forming monophyletic groups (Fig. 2). This was previously shown by examination of SSU-rRNA, gGAPDH, cytochrome $b$ and cruzipain (Cavazzana et al., 2010; Maia da Silva et al., 2009; Lima et al., 2012a,b), and by comparative proteomic analysis (Telleria et al., 2010). More recently, Lima et al. (2015) provided strong evidence for the recognition of Tc-bat as an additional DTU, but unfortunately for our analysis DNA from this lineage was not available. 
In conclusion, the hsp70-derived Trypanosoma phylogeny adds to the existing evidence towards classification into clades. The position of T. theileri remained however unclear. The hsp70 gene phylogeny could identify three $T$. cruzi groups (TcI, TcIII, and TcII+V+VI), but did not reflect the hybrid DTUs' separate evolution. The $h s p 70$ gene was shown adequate for studying Trypanosoma evolution, and has been successfully applied for typing in various clinical samples of another kinetoplastid, Leishmania (Graça et al. 2012; Fraga et al., 2012; García et al. 2004; Montalvo et al., 2014; Veland et al. 2012). Therefore, it is a promising diagnostic marker for the Trypanosoma genus as well, although more variable markers are needed to distinguish the Trypanozoon species. In fact, some typing assays have already been developed (Cuervo et al., 2013; Fraga et al., 2014; Rozas et al., 2007, 2008; Westenberger et al., 2005). Such typing assays should comply with a general consensus phylogeny, established by analyzing many genes from all species in parallel, or ultimately the entire genome.

\section{Acknowledgments}

The authors would like to thank all colleagues and institutes who kindly donated the Trypanosoma reference strains and DNA: F. Guhl (Universidad de los Andes, Bogota, Colombia), M. D. Lewis and M. A. Miles (London School of Hygiene and Tropical Medicine, London, United Kingdom), H. J. Carrasco (Instituto de Medicina Tropical, Caracas, Venezuela), J. A. Costales and M. J. Grijalva (Centro de Investigación en Enfermedades Infecciosas (CIEI), Pontificia Universidad Católica del Ecuador, Ecuador; and Tropical Disease Institute (TDI), Ohio University, USA) and R. Fikru (University of Addis Ababa, Ethiopia). The authors are thankful to B. Cuypers (Institute of Tropical Medicine, Antwerp, Belgium), J. Cauchard (French Agency for Food, Environmental and Occupational Health \& Safety, France), J. Wilkes (University of Glasgow, UK), and F. Claes (Food and Agriculture Organization, Italy) for providing the whole 
genome sequences used in the study. This work was funded by the third framework agreement of the Belgian Directorate General for Development with ITM Antwerp.

\section{Legends.}

Fig. 1. Geographical origin of the 58 strains and isolates with known origin included in this study. Strains are assigned at country level, the position of the symbols within a country has no meaning. The symbols represent different species, the numbers next to the symbols indicate how many strains were included in our analysis. The first number between parentheses represents the number of sequences used in our alignments, while the second number indicates how many were sequenced and submitted to GenBank for this study.

Fig. 2. Neighbor-Joining phylogeny of the hsp70 nucleotide sequences belonging to 11 Trypanosoma species. Distances were estimated using the Kimura 2-parameter model. Bootstrap support of the branches was inferred from 2000 replicates, and is given in percentages at the internodes when exceeding $70 \%$ (first value). For comparison, also the bootstrap values of the Maximum Parsimony (Fig. S1) and Maximum Likelihood (Fig. S2) trees are shown for each respective group (second and third values respectively). The tree is drawn to the scale at the bottom, expressed as distance per nucleotide. The tree was rooted with the sequences of Paratrypanosoma confusum and Leishmania spp. (L. aethiopica, L. major, L. tropica, L. donovani, L. infantum, L. amazonensis, L. mexicana, L. garnhami, L. braziliensis, L. peruviana, L. lainsoni, L. guyanensis, L. panamensis, L. naiffi). The names on the branches represent the classical subgenus classification of Hoare (1971). The Stercoraria and Salivaria sections are indicated on the left. Clades proposed in Simpson et al. (2006) and monophyletic groups from other reports are depicted at the right by vertical lines, for SSU-rDNA (Cavazzana et al., 2010; 
Stevens and Gibson, 1999); gGAPDH (Hamilton et al., 2005); and SSU-rDNA + gGAPDH (Lima et al., 2013). The vertical black and grey lines depict monophyletic clusters from these analyses, with the numbers on their right representing the bootstrap support in percentages. It should be noted that none of these studies used an identical strain and species set, so comparing them is indicative. Strains are identified using the code as in Table S1, followed by the species or subspecies (Tbb: T. brucei brucei; Tbg: T. brucei gambiense; Tbr: T. brucei rhodesiense; Tca: T. carassi; Tcm: T. cruzi marinkellei; Tco: T. congolense; Teq: T. equiperdum, Tev: T. evansi; Tgr: T. grayi, Tle: T. lewisi; Tra: T. rangeli; Tth: T. theileri; Tvi: T. vivax; Tc: T. cruzi with DTUs I-VI indicated as TcI-TcVI), and the accession number in GenBank, TrypTriDB, or GeneDB (C refers to unpublished confidential data from whole genome sequences).

Fig. 3. Phylogenetic network of the Trypanosoma hsp70 sequences. The network was constructed using the Neighbor-Net algorithm (Bryant and Moulton, 2004), excluding all conserved sites. The Kimura 2-parameter model for nucleotides was used, calculating the fraction of differences between each pair of sequences. Each of the four panels (A-D) is drawn to the scale indicated, expressed as distance per nucleotide counted over variable sites in the $h s p 70$ alignment. The numbers with the splits represent bootstrap values from 2000 replicates in percentages. (A) Complete network with representation of the three groups shown in more detail in the remaining panels; (B) T. rangeli clade; (C) T. brucei clade (Trypanozoon); (D) T. cruzi clade. Within the T. cruzi clade, splits defining the discrete typing units (DTUs) are indicated by dotted bows, with their bootstrap values. All features and abbreviations are as in Table S1.

Fig. 4. Neighbor-Joining phylogeny based on concatenated SSU-rDNA+gGADPH+hsp70 sequences belonging to 9 Trypanosoma species. Distances were estimated using the Kimura 
2-parameter model. Bootstrap support of the branches was inferred from 2000 replicates, and is given in percentages at the internodes when exceeding $70 \%$ (first value). For comparison, also the bootstrap values of the Maximum Parsimony and Maximum Likelihood trees are shown for each respective group (second and third values respectively). The tree is drawn to the scale at the bottom, expressed as distances per nucleotide. The tree was rooted with the sequences of Paratrypanosoma confusum and Leishmania major. The Stercoraria and Salivaria sections are indicated on the left. Only one strain was used for each species. It should be noted that in some cases it was impossible to use identical strains for each gene because sequences were not available (Table S2). Strains are identified using the species or subspecies (abbreviations as in Fig. 2). 


\section{References}

Amer, S., Ryu, O., Tada, C., Fukuda, Y., Inoue, N., Nakai, Y., 2011. Molecular identification and phylogenetic analysis of Trypanosoma evansi from dromedary camels (Camelus dromedarius) in Egypt, a pilot study. Acta Trop. 117, 39-46.

Añez, N., 1982. Studies on Trypanosoma rangeli Tejera, 1920. IV--A reconsideration of its systematic position. Mem. Inst. Oswaldo Cruz. 77, 405-415.

Arisue, N., Hashimoto, T., Yoshikawa, H., Nakamura, Y., Nakamura, G., Nakamura, F., Yano, T. A., Hasegawa, M., 2002a. Phylogenetic position of Blastocystis hominis and of stramenopiles inferred from multiple molecular sequence data. J. Eukaryot. Microbiol. 49, $42-43$.

Arisue, N., Sánchez, L. B., Weiss, L. M., Müller, M., Hashimoto, T., 2002b. Mitochondrial-type hsp70 genes of the amitochondriate protists, Giardia intestinalis, Entamoeba histolytica and two microsporidians. Parasitol. Int. 51, 9-16.

Barrett, M. P., Burchmore, R. J., Stich, A., Lazzari, J. O., Frasch, A. C., Cazzulo, J. J., Krishna, S., 2003. The trypanosomiases. Lancet. 362, 1469-1480.

Brisse, S., Dujardin, J. C., Tibayrenc, M., 2000. Identification of six Trypanosoma cruzi lineages by sequence-characterised amplified region markers. Mol. Biochem. Parasitol. 111, 95105.

Bryant, D., Moulton, V., 2004. Neighbor-Net: An agglomerative method for the construction of phylogenetic networks. Mol. Biol. Evol. 21, 255-265.

Caballero, Z .C., Costa-Martins, A. G., Ferreira, R. C., Alves, J. M. P., Serrano, M. G., Camargo, E. P., Buck, G. A., Minoprio, P., Teixeira, M. M. G., 2015. Phylogenetic and syntenic data support a single horizontal transference to a Trypanosoma ancestor of a prokaryotic 
proline racemase implicated in parasite evasion from host defences. Parasit. Vectors. 8, 222.

Cavazzana, M., Jr., Marcili, A., Lima, L., da Silva, F. M., Junqueira, A. C., Veludo, H. H., Viola, L. B., Campaner, M., Nunes, V. L., Paiva, F., Coura, J. R., Camargo, E. P., Teixeira, M. M. G., 2010. Phylogeographical, ecological and biological patterns shown by nuclear (ssrRNA and gGAPDH) and mitochondrial (Cyt b) genes of trypanosomes of the subgenus Schizotrypanum parasitic in Brazilian bats. Int. J. Parasitol. 40, 345-355.

Cortez, A. P., Ventura, R. M., Rodrigues, A. C., Batista, J. S., Paiva, F., Anez, N., Machado, R. Z., Gibson, W. C., Teixeira, M. M. G., 2006. The taxonomic and phylogenetic relationships of Trypanosoma vivax from South America and Africa. Parasitology. 133, 159-169.

Cuervo, C., Thomas, M. C., López, M. C., Puerta, C. J., 2013. Sequence polymorphism in the Trypanosoma rangeli HSP70 coding genes allows typing of the parasite KP1(+) and KP1(-) groups. Exp. Parasitol. 133, 447-453.

Eck, R. V., Dayhoff, M. O., 1966. Atlas of Protein Sequence and Structure. National Biomedical Research Foundation, Silver Springs, Maryland.

Felsenstein, J., 1985. Confidence limits on phylogenies: An approach using the bootstrap. Evolution. 39, 783-791.

Ferreira, R. C., Briones, M. R., 2012. Phylogenetic evidence based on Trypanosoma cruzi nuclear gene sequences and information entropy suggests that inter-strain intragenic recombination is a basic mechanism underlying the allele diversity of hybrid strains. Infect. Genet. Evol. 12, 1064-1071.

Fitch, W. M., 1971. Towards defining the course of evolution: Minimum change for a specific tree topology. Syst. Zool. 20, 406-416. 
Flores-Lopez, C. A., Machado, C. A., 2011. Analyses of 32 loci clarify phylogenetic relationships among Trypanosoma cruzi lineages and support a single hybridization prior to human contact. PLoS. Negl. Trop. Dis. 5, e1272.

Folgueira, C., Requena, J. M., 2007. A postgenomic view of the heat shock proteins in kinetoplastids. FEMS. Microbiol. Rev. 31, 359-377.

Fraga, J., Montalvo, A. M., De Doncker, S., Dujardin, J. C., Van der Auwera, G., 2010. Phylogeny of Leishmania species based on the heat shock protein 70 gene. Infect. Genet. Evol. 10, 238-245.

Fraga, J., Montalvo, A. M., Van der Auwera, G., Maes, I., Dujardin, J. C., Requena, J. M., 2013. Evolution and species discrimination according to the Leishmania heat-shock protein 20 gene. Infect. Genet. Evol. 18, 229-237.

Fraga, J., Veland, N., Montalvo, A. M., Praet, N., Boggild, A., Valencia, B. M., Arévalo, J., Llanos-Cuentas, A., Dujardin, J. C., Van der Auwera, G., 2012. Accurate and rapid species typing from cutaneous and mucocutaneous leishmaniasis lesions of the New World. Diagn. Microbiol. Infect. Dis. 74, 142-150.

Fraga, J., Fernandez-Calienes, A., Montalvo, A. M., Maes, I., Dujardin, J. C., Van der Auwera, G., 2014. Differentiation between Trypanosoma cruzi and Trypanosoma rangeli using heat-shock protein 70 polymorphisms. Trop. Med. Int. Health. 19, 195-206.

Garcia, L., Kindt, A., Bermudez, H., Llanos-Cuentas, A., De Doncker, S., Arevalo, J., Wilber Quispe Tintaya, K., Dujardin, J. C., 2004. Culture-independent species typing of neotropical Leishmania for clinical validation of a PCR-based assay targeting heat shock protein 70 genes. J. Clin. Microbiol. 42, 2294-2297.

Gibson, W., 2007. Resolution of the species problem in African trypanosomes. Int. J. Parasitol. 37, 829-838. 
Graça, G. C., Volpini, A. C., Romero, G. A., Oliveira Neto, M. P., Hueb, M., Porrozzi, R., Boité, M. C., Cupolillo, E., 2012. Development and validation of PCR-based assays for diagnosis of American cutaneous leishmaniasis and identification of the parasite species. Mem. Inst. Oswaldo Cruz. 107, 664-674.

Hamilton, P. B., Gibson, W. C., Stevens, J. R., 2007. Patterns of co-evolution between trypanosomes and their hosts deduced from ribosomal RNA and protein-coding gene phylogenies. Mol. Phylogenet. Evol. 44, 15-25.

Hamilton, P. B., Stevens, J. R., Gaunt, M. W., Gidley, J., Gibson, W. C., 2004. Trypanosomes are monophyletic: evidence from genes for glyceraldehyde phosphate dehydrogenase and small subunit ribosomal RNA. Int. J. Parasitol. 34, 1393-1404.

Hartl, F. U., Hayer-Hartl, M., 2002. Molecular chaperones in the cytosol: From nascent chain to folded protein. Science. 295, 1852-1858.

Hoare, C. A., 1972. The Trypanosomes of Mammals. Blackwell Scientific Publications, Oxford.

Hughes, A. L., Piontkivska, H., 2003. Molecular phylogenetics of Trypanosomatidae: contrasting results from 18S-rRNA and protein phylogenies. Kinetoplastid. Biol. Dis. 2, 15.

Huson, D. H., 1998. SplitsTree: analyzing and visualizing evolutionary data. Bioinformatics. 14, $68-73$.

Huson, D. H., Bryant, D., 2006. Application of phylogenetic networks in evolutionary studies. Mol. Biol. Evol. 23, 254-267.

Kelly, S., Ivens, A., Manna, P. T., Gibson, W., Field, M. C., 2014. A draft genome for the African crocodilian trypanosome Trypanosoma grayi. Sci. Data. 1, 140024.

Kimura, M., 1980. A simple method for estimating evolutionary rate of base substitutions through comparative studies of nucleotide sequences. J. Mol. Evol. 16, 111-120. 
Langkjaer, R. B., Vigre, H., Enemark, H. L., Maddox-Hyttel, C., 2007. Molecular and phylogenetic characterization of Cryptosporidium and Giardia from pigs and cattle in Denmark. Parasitology. 134, 339-350.

Leonard, G., Soanes, D. M., Stevens, J. R., 2011. Resolving the question of trypanosome monophyly: a comparative genomics approach using whole genome data sets with low taxon sampling. Infect. Genetic. Evol. 11, 955-959.

Lima, L., Espinosa-Alvarez, O., Hamilton, P. B., Neves, L., Takata, C. S., Campaner, M., Attias, M., de Souza, W., Camargo, E. P., Teixeira, M. M. G., 2013. Trypanosoma livingstonei: a new species from African bats supports the bat seeding hypothesis for the Trypanosoma cruzi clade. Parasit. Vectors. 6, 221.

Lima, L., Espinosa-Álvarez, O., Ortiz, P. A., Trejo-Varón, J. A., Carranza, J. C., Pinto, C. M., Serrano, M. G., Buck, G. A., Camargo, E. P., Teixeira, M. M. G., 2015. Genetic diversity of Trypanosoma cruzi in bats, and multilocus phylogenetic and phylogeographical analyses supporting Tcbat as an independent DTU (discrete typing unit). Acta. Trop. 151, 166-177.

Lima, L., Ortiz, P. A., da Silva, F. M., Alves, J. M., Serrano, M.G., Cortez, A. P., Alfieri, S. C., Buck, G. A., Teixeira, M. M. G., 2012a. Repertoire, genealogy and genomic organization of cruzipain and homologous genes in Trypanosoma cruzi, T. cruzi-like and other trypanosome species. PloS. One. 7, e38385.

Lima, L., Silva, F. M., Neves, L., Attias, M., Takata, C. S., Campaner, M., de Souza, W., Hamilton, P. B., Teixeira, M. M. G., 2012b. Evolutionary insights from bat trypanosomes: morphological, developmental and phylogenetic evidence of a new species, Trypanosoma (Schizotrypanum) erneyi sp. nov., in African bats closely related to Trypanosoma (Schizotrypanum) cruzi and allied species. Protist. 163, 856-872. 
Lukeš, J., Jirkû, M., Dolezel, D., Kral'ová, I., Hollar, L., Maslov, D. A., 1997. Analysis of ribosomal RNA genes suggests that trypanosomes are monophyletic. J. Mol. Evol. 44, $521-527$.

Maia Da Silva, F., Junqueira, A. C., Campaner, M., Rodrigues, A. C., Crisante, G., Ramirez, L. E., Caballero, Z. C., Monteiro, F. A., Coura, J. R., Anez, N., Teixeira, M. M. G., 2007. Comparative phylogeography of Trypanosoma rangeli and Rhodnius (Hemiptera: Reduviidae) supports a long coexistence of parasite lineages and their sympatric vectors. Mol. Ecol. 16, 3361-3373.

Maia da Silva, F., Marcili, A., Lima, L., Cavazzana, M., Jr., Ortiz, P.A., Campaner, M., Takeda, G. F., Paiva, F., Nunes, V. L., Camargo, E. P., Teixeira, M. M. G., 2009. Trypanosoma rangeli isolates of bats from Central Brazil: genotyping and phylogenetic analysis enable description of a new lineage using spliced-leader gene sequences. Acta. Trop. 109, 199207.

Maia da Silva, F., Rodrigues, A. C., Campaner, M., Takata, C. S., Brigido, M. C., Junqueira, A. C., Coura, J. R., Takeda, G. F., Shaw, J. J., Teixeira, M. M. G., 2004. Randomly amplified polymorphic DNA analysis of Trypanosoma rangeli and allied species from human, monkeys and other sylvatic mammals of the Brazilian Amazon disclosed a new group and a species-specific marker. Parasitology. 128, 283-294.

Marcili, A., Lima, L., Cavazzana, M., Junqueira, A. C., Veludo, H. H., Maia Da Silva, F., Campaner, M., Paiva, F., Nunes, V. L., Teixeira, M. M. G., 2009. A new genotype of Trypanosoma cruzi associated with bats evidenced by phylogenetic analyses using SSU rDNA, cytochrome $\mathrm{b}$ and Histone $\mathrm{H} 2 \mathrm{~B}$ genes and genotyping based on ITS1 rDNA. Parasitology. 136, 641-655. 
Miles, M. A., Llewellyn, M. S., Lewis, M. D., Yeo, M., Baleela, R., Fitzpatrick, S., Gaunt, M. W., Mauricio, I. L., 2009. The molecular epidemiology and phylogeography of Trypanosoma cruzi and parallel research on Leishmania: looking back and to the future. Parasitology. 136, 1509-1528.

Montalvo, A. M., Fraga, J., El Safi, S., Gramiccia, M., Jaffe, C. L., Dujardin, J. C., Van der Auwera, G., 2014. Direct Leishmania species typing in Old World clinical samples: evaluation of 3 sensitive methods based on the heat-shock protein 70 gene. Diagn. Microbiol. Infect. Dis. 80, 35-39.

Nei, M., Gojobori T., 1986. Simple methods for estimating the numbers of synonymous and nonsynonymous nucleotide substitutions. Mol. Biol. Evol. 3, 418-426.

Ortiz, P.A., Maia da Silva, F., Cortez, A.P., Lima, L., Campaner, M., Pral, E.M., Alfieri, S. C., Teixeira, M. M. G., 2009. Genes of cathepsin L-like proteases in Trypanosoma rangeli isolates: markers for diagnosis, genotyping and phylogenetic relationships. Acta. Trop. $112,249-259$.

Requena, J. M., Lopez, M. C., Jimenez-Ruiz, A., de la Torre, J. C., Alonso, C., 1988. A head-totail tandem organization of hsp70 genes in Trypanosoma cruzi. Nucleic. Acids. Res. 16, $1393-1406$.

Requena, J.M., Montalvo, A.M., Fraga, J., 2015. Molecular chaperones of Leishmania: Central players in many stress-related and -unrelated physiological processes. Biomed. Res. Int. 301326.

Rodrigues, A. C., Paiva, F., Campaner, M., Stevens, J. R., Noyes, H. A., Teixeira, M. M. G., 2006. Phylogeny of Trypanosoma (Megatrypanum) theileri and related trypanosomes reveals lineages of isolates associated with artiodactyl hosts diverging on SSU and ITS ribosomal sequences. Parasitology. 132, 215-224. 
Rozas, M., De Doncker, S., Adaui, V., Coronado, X., Barnabe, C., Tibyarenc, M., Solari, A., Dujardin, J. C., 2007. Multilocus Polymerase Chain Reaction Restriction FragmentLength Polymorphism Genotyping of Trypanosoma cruzi (Chagas Disease): Taxonomic and Clinical Applications. J. Infect. Dis. 195, 1381-1388.

Rozas, M., De Doncker, S., Adaui, V., Coronado, X., Barnabe, C., Tibyarenc, M., Solari, A., Dujardin, J. C., 2008. Evolutionary history of Trypanosoma cruzi according to antigen genes. Parasitology. 135, 1157-1164.

Simpson, A. G., Stevens, J. R., Lukeš, J., 2006. The evolution and diversity of kinetoplastid flagellates. Trends. Parasitol. 22, 168-174.

Stevens, J. R., 2008. Kinetoplastid phylogenetics, with special reference to the evolution of parasitic trypanosomes. Parasite. 15, 226-232.

Stevens, J. R., Gibson, W., 1999. The molecular evolution of trypanosomes. Parasitol. Today 15, 432-437.

Stevens, J., Rambaut, A., 2001. Evolutionary rate differences in trypanosomes. Infect. Genet. Evol. 1, 143-150.

Sulaiman, I. M., Morgan, U. M., Thompson, R. C., Lal, A. A., Xiao, L., 2000. Phylogenetic relationships of Cryptosporidium parasites based on the 70-kilodalton heat shock protein (HSP70) gene. Appl. Environ. Microbiol. 66, 2385-2391.

Tamura, K., Peterson, D., Peterson, N., Stecher, G., Nei, M., Kumar, S., 2011. MEGA5: molecular evolutionary genetics analysis using maximum likelihood, evolutionary distance, and maximum parsimony methods. Mol. Biol. Evol. 28, 2731-2739.

Telleria, J., Biron, D. G., Brizard, J. P., Demettre, E., Seveno, M., Barnabe, C., Ayala, F. J., Tibayrenc, M., 2010. Phylogenetic character mapping of proteomic diversity shows high 
correlation with subspecific phylogenetic diversity in Trypanosoma cruzi. Proc. Natl. Acad. Sci. U S A. 107, 20411-20416.

Tibayrenc M, Ayala F. J., 2012. Reproductive clonality of pathogens: a perspective on pathogenic viruses, bacteria, fungi, and parasitic protozoa. Proc. Natl. Acad. Sci. U.S.A. 109,3305-3313.

Vallejo, G. A., Guhl, F., Carranza, J. C., Moreno, J., Triana, O., Grisard, E. C., 2003. Parity between kinetoplast DNA and mini-exon gene sequences supports either clonal evolution or speciation in Trypanosoma rangeli strains isolated from Rhodnius colombiensis, $R$. pallescens and $R$. prolixus in Colombia. Infect. Genet. Evol. 3, 39-45.

Vallejo, G. A., Guhl, F., Chiari, E., Macedo, A. M., 1999. Species specific detection of Trypanosoma cruzi and Trypanosoma rangeli in vector and mammalian hosts by polymerase chain reaction amplification of kinetoplast minicircle DNA. Acta. Trop. 72, 203-212.

Vallejo, G. A., Guhl, F., Schaub, G. A., 2009. Triatominae-Trypanosoma cruzi/T. rangeli:Vector-parasite interactions. Acta. Trop. 110, 137-147.

Veland, N., Boggild, A. K., Valencia, C., Valencia, B. M., Llanos-Cuentas, A., Van der Auwera, G., Dujardin, J. C., Arevalo, J., 2012. Leishmania (Viannia) species identification on clinical samples from cutaneous leishmaniasis patients in Peru: assessment of a molecular stepwise approach. J. Clin. Microbiol. 50, 495-498.

Vickerman, K., 1976. The Diversity of the kinetoplastid flagellates, in: Lumsden, W. H. R., Evans, D. A. (Eds), Biology of the Kinetoplastida, Academic Press, London/New York/San Francisco, pp. 1-34. 
Votýpka, J., d'Avila-Levy, C. M., Grellier, P., Maslov, D. A., Lukeš, J., Yurchenko, V., 2015. New Approaches to Systematics of Trypanosomatidae: Criteria for Taxonomic (Re)description. Trends. Parasitol. 31, 460-469.

Westenberger, S. J., Barnabe, C., Campbell, D. A., Sturm, N. R., 2005. Two hybridization events define the population structure of Trypanosoma cruzi. Genetics. 171, 527-543.

Yamasaki, M., Inokuma, H., Sugimoto, C., Shaw, S. E., Aktas, M., Yabsley, M. J., Yamato, O., Maede, Y., 2007. Comparison and phylogenetic analysis of the heat shock protein 70 gene of Babesia parasites from dogs.Vet. Parasitol. 145, 217-227.

Yamasaki, M., Tajima, M., Lee, K. W., Jeong, J. R., Yamato, O., Maede, Y., 2002. Molecular cloning and phylogenetic analysis of Babesia gibsoni heat shock protein 70. Vet. Parasitol. 11, 123-129.

Zingales, B., Miles, M. A., Campbell, D. A., Tibayrenc, M., Macedo, A. M., Teixeira, M. M. G., Schijman, A.G., Llewellyn, M.S., Lages-Silva, E., Machado, C.R., Andrade, S. G., Sturm, N. R., 2012. The revised Trypanosoma cruzi subspecific nomenclature: rationale, epidemiological relevance and research applications. Infect. Genet. Evol. 12, 240-253. 


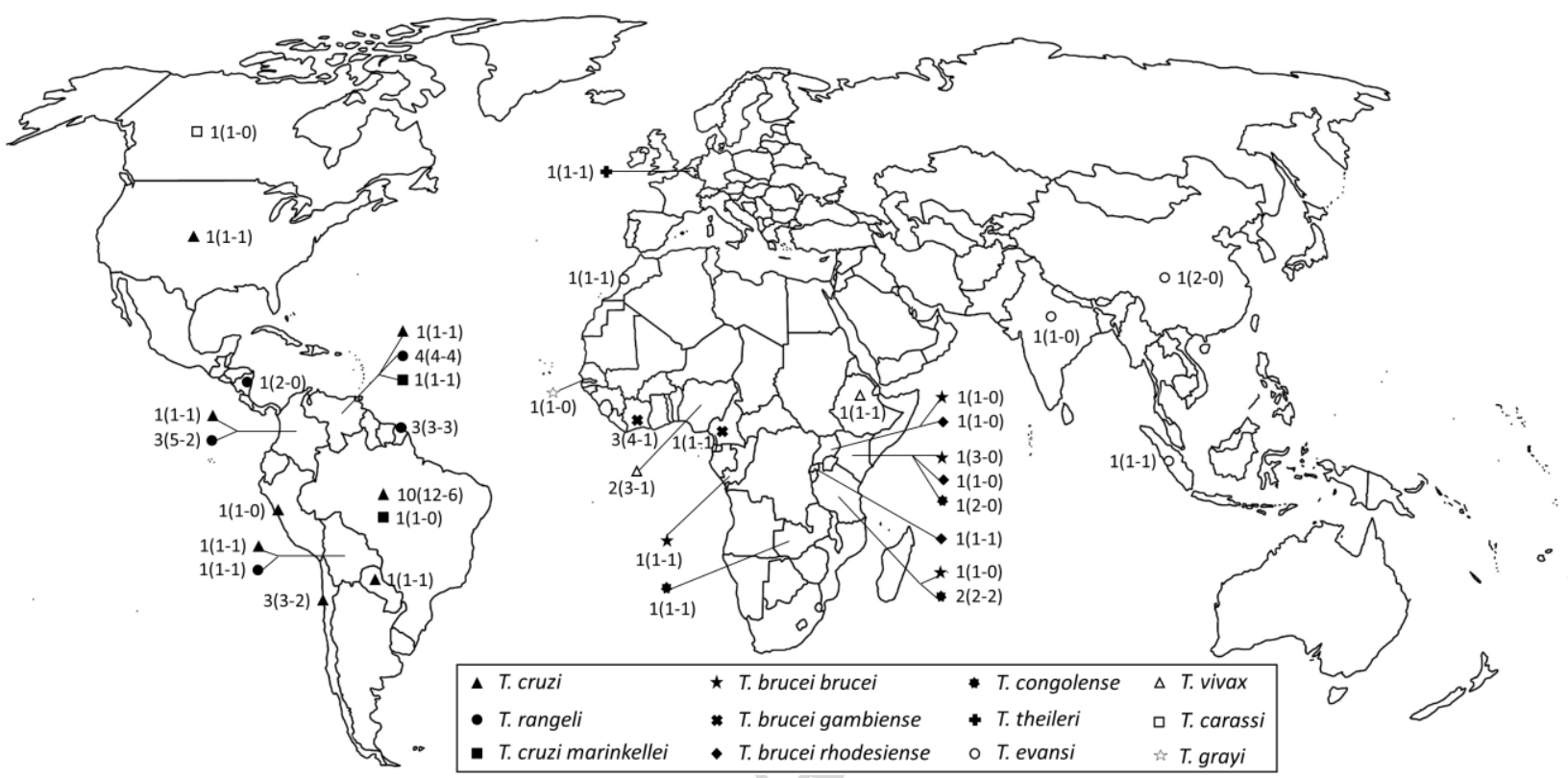

Fig. 1 


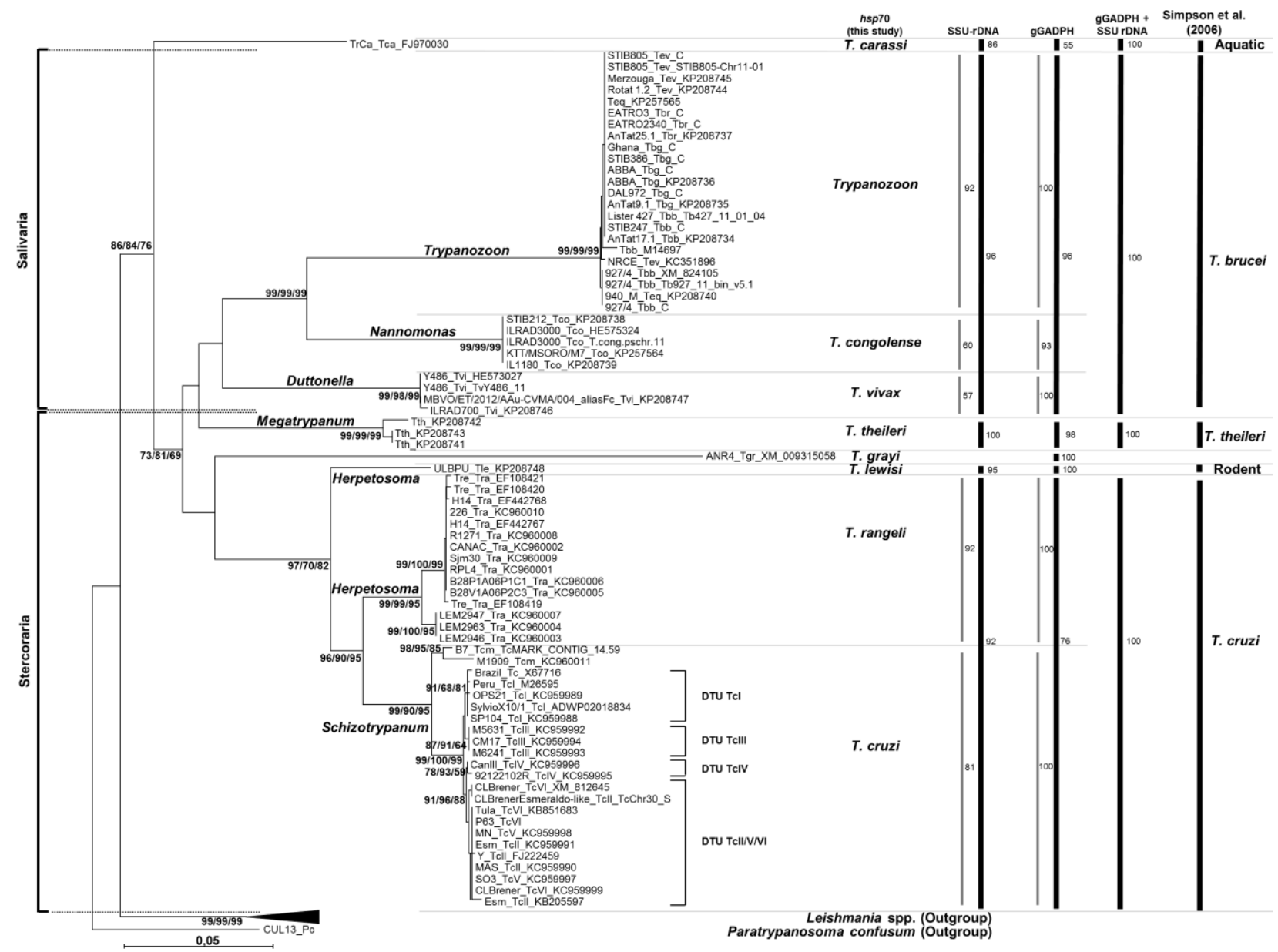

Fig. 2 


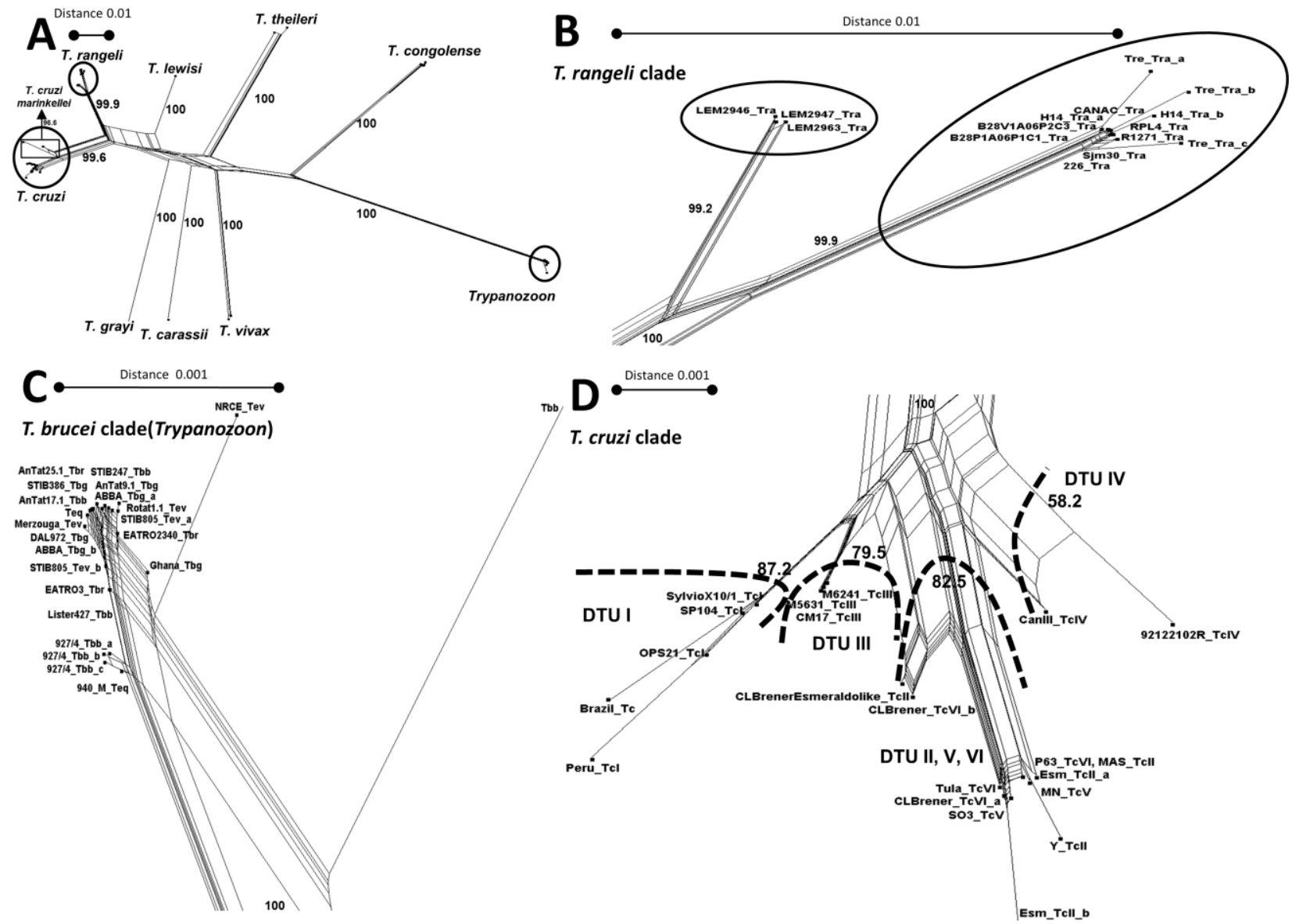

Fig. 3 


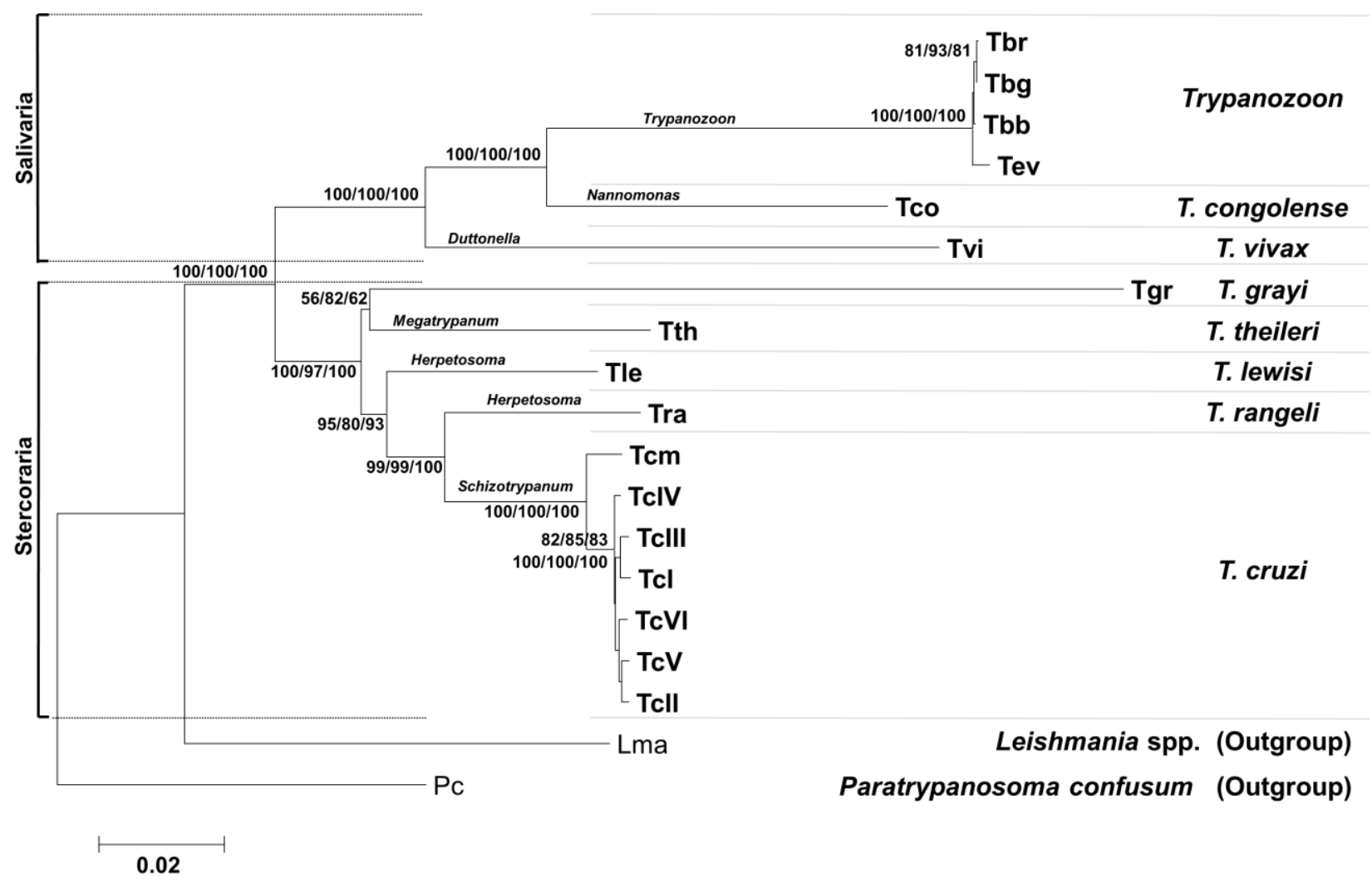

Fig. 4 
Table 1. Taxonomy of the Trypanosoma genus

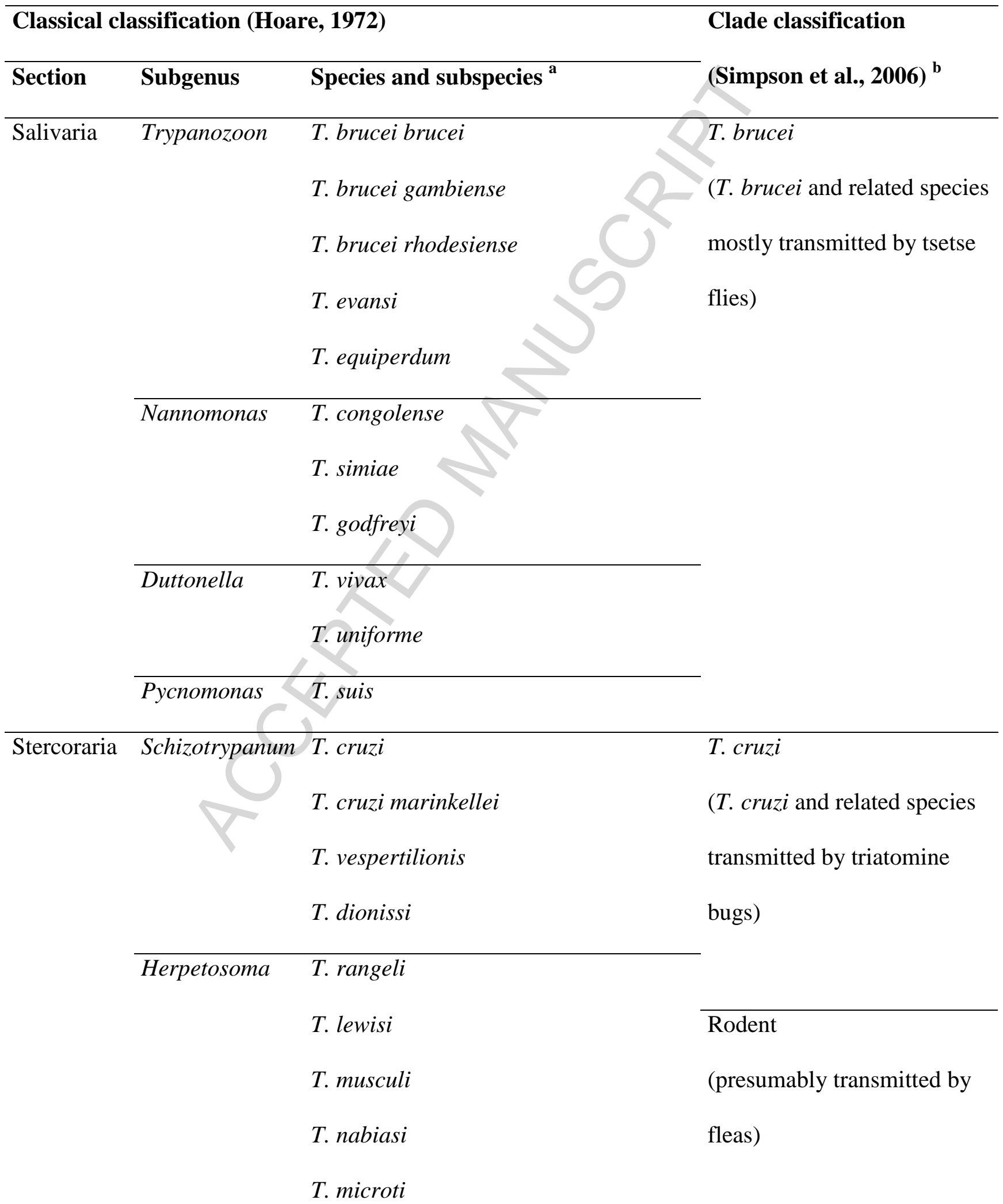




Megatrypanum
T. theileri
T. conorhini
T. minasense
T. pestanai
T. cyclops
T. theodori

T. carassi, T. cobitis, T. granulosum,

Aquatic

T. sinipercea, T. ophiocephali, (transmitted by insects and

T. chelodinae, T. nudigobii, leeches, also includes

T. blennidini, T. haploblephari, trypanosomes of platypuses

T. boissoni, T. capigobii, and aquatic tortoises)

T. semegalense, T. murmanense,

T. pleuronectidium, T. triglae,

T. rotatorium, T. ranarum, T. chattoni,

T. binneyi, T. therezieni, T. mega,

T. neveulemairei, T. fallisi

T. avium, T. bennetti, T. corvi,

T. culicavium, T. gallinarum,

T. polygranularis, T. anguiformis
Avian

(transmitted primarily by

black flies and hippoboscid

flies)

a Listing contains only the most frequently phylogenetically studied species.

b Species listed with each clade were not specified in this paper. 
Table 2. Primers used for $h s p 70$ gene sequencing and PCR.

\begin{tabular}{lll}
\hline Primer & Primer Sequence $\left(\mathbf{5}^{\prime} \mathbf{- 3}^{\prime}\right)$ & Nucleotide position $^{\mathbf{a}}$ \\
\hline HSP70sen $^{\mathrm{b}}$ & GACGGTGCCTGCCTACTTCAA & $435-455$ \\
HSP70T-F308 $^{\mathrm{c}}$ & CAAGCGCAAGAACAAGGGCAAGG & $741-763$ \\
HSP70T-F813 $^{\mathrm{c}}$ & CTGATCAAGCGCAACACGACG & $1246-1263$ \\
HSP70T-R564 $^{\mathrm{c}}$ & GCACGCTTGTCCATCTTGGC & $998-979$ \\
HSP70T-R1069 $^{\mathrm{c}}$ & CGCTTACCGGTGCCCTTCTCCTC & $1501-1480$ \\
HSP70ant $^{\mathrm{b}}$ & CCGCCCATGCTCTGGTACATC & $1856-1836$ \\
\hline
\end{tabular}

a The annealing position of the primers is given relative to GenBank accession XM_812645 (T. cruzi strain CL Brener).

b Primers used for PCR amplification (Garcia et al., 2004).

c Primer used for sequencing (Fraga et al., 2014). 


\section{Highlights}

- The heat-shock protein 70 gene is a suitable molecular marker for studying Trypanosoma phylogeny.

- Phylogeny based on hsp70 supports classification of Trypanosoma in clades sensu Simpson et al. (2006).

- In the T. cruzi clade three groups are discriminated: TcI, TcIII, and TcII+V+VI, while TcIV is not well supported. 